Kragujevac Journal of Mathematics

Volume 44(4) (2020), Pages 523-532.

\title{
ON EQUIENERGETIC, HYPERENERGETIC AND HYPOENERGETIC GRAPHS
}

\author{
SAMIR K. VAIDYA ${ }^{1}$ AND KALPESH M. POPAT ${ }^{2}$
}

\begin{abstract}
The eigenvalue of a graph $G$ is the eigenvalue of its adjacency matrix and the energy $E(G)$ is the sum of absolute values of eigenvalues of graph $G$. Two non-isomorphic graphs $G_{1}$ and $G_{2}$ of the same order are said to be equienergetic if $E\left(G_{1}\right)=E\left(G_{2}\right)$. The graphs whose energy is greater than that of complete graph are called hyperenergetic and the graphs whose energy is less than that of its order are called hypoenergetic graphs. The natural question arises: Are there any pairs of equienergetic graphs which are also hyperenergetic (hypoenergetic)? We have found an affirmative answer of this question and contribute some new results.
\end{abstract}

\section{INTRODUCTION}

We begin with finite connected and undirected graphs without loops and multiple edges. The terms not defined here are used in sense of Balakrishnan and Ranganathan [1] or Cvetković et al. [5]. The adjacency matrix of a graph $G$ with vertices $v_{1}, v_{2}, \ldots, v_{n}$ is an $n \times n$ matrix $\left[a_{i j}\right]$ such that,

$$
a_{i j}= \begin{cases}1, & \text { if } v_{i} \text { is adjacent with } v_{j}, \\ 0, & \text { otherwise }\end{cases}
$$

The eigenvalues of adjacency matrix of graph is known as eigenvalues of graph. The set of eigenvalues of the graph with their multiplicities is known as spectrum of the graph. Hence,

$$
\operatorname{spec}(G)=\left(\begin{array}{cccc}
\lambda_{1} & \lambda_{2} & \cdots & \lambda_{n} \\
m_{1} & m_{2} & \cdots & m_{n}
\end{array}\right)
$$

Key words and phrases. Equienergetic, hyperenergetic, hypoenergetic. 2010 Mathematics Subject Classification. Primary: 05C50, 05C76.

DOI 10.46793/KgJMat2004.523V

Received: June 30, 2017.

Accepted: June 15, 2018. 
Two non-isomorphic graphs are said to be cospectral if they have same spectra, otherwise they are known as non-cospectral. Let $G$ be a graph on $n$ vertices and $\lambda_{1}, \lambda_{2}, \ldots, \lambda_{n}$ be the eigenvalues of $G$. The energy of a graph $G$ is the sum of absolute values of the eigenvalues of graph $G$ and denoted by $E(G)$. Hence,

$$
E(G)=\sum_{i=1}^{n}\left|\lambda_{i}\right| .
$$

The concept of energy was introduced by Gutman [6]. A brief account of energy of graph can be found in Cvetković et al. [5] and Li et al. [10]. Two non-isomorphic graphs $G_{1}$ and $G_{2}$ of same order are said to be equienergetic if $E\left(G_{1}\right)=E\left(G_{2}\right)$.

Ramane et al. [12,13] have proved that if $G_{1}$ and $G_{2}$ are regular graphs of same order then for $k \geq 2, L^{k}\left(G_{1}\right)$ and $L^{k}\left(G_{2}\right), \overline{L^{k}\left(G_{1}\right)}$ and $\overline{L^{k}\left(G_{2}\right)}$ are equienergetic. Here, $L^{k}(G)$ is called iterated line graph of $G$.

Some equienergetic graphs have been described in Li et al. [10], while a symmetric computer aided study have carried out for equienergetic trees $[2,11]$. Some open problem on equienergetic graphs were posted in [8]. To find out non-copspectral equienergetic graphs other than trees is challenging and interesting as well. We take up this problems and construct a pair of graphs which are equienergetic.

In 1978 Gutman [6] conjectured that among all graphs with $n$ vertices, the complete graph $K_{n}$ has the maximum energy. This was disproved by Walikar et al. [16] and was defined the concept of hyperenergetic graphs whose energy is greater than that of complete graphs. Gutman [7] has proved that hyperenergetic graphs on $n$ vertices exist for all $n \geq 8$ and there are no hyperenergetic graphs on less than 8 vertices.

A graph $G$ on order $n$ is said to be hypoenergetic [3] if $E(G)$ is less than its order otherwise it is said to be non-hypoenergetic [4]. In 2007 Gutman [9] have proved that if the graph $G$ is regular of any non-zero degree, then $G$ is non hypoenergetic.

The present work is aimed to contribute to find families of hyperenergetic and hypoenergetic.

The splitting graph $S^{\prime}(G)$ of a graph $G$ is obtained by adding to each vertex $v$ a new vertex $v^{\prime}$, such that $v^{\prime}$ is adjacent to every vertex that is adjacent to $v$ in $G$. The shadow graph $D_{2}(G)$ of a connected graph $G$ is constructed by taking two copies of $G$ say $G^{\prime}$ and $G^{\prime \prime}$. Join each vertex $u^{\prime}$ in $G^{\prime}$ to the neighbors of the corresponding vertex $u^{\prime \prime}$ in $G^{\prime \prime}$. Vaidya and Popat [15] have proved that for any graph $G, E\left(S^{\prime}(G)\right)=\sqrt{5} E(G)$ and $E\left(D_{2}(G)\right)=2 E(G)$.

The $m$-splitting graph $\operatorname{Spl}_{m}(G)$ of a graph $G$ is obtained by adding to each vertex $v$ of $G$ new $m$ vertices, say $v_{1}, v_{2}, v_{3}, \ldots, v_{m}$, such that $v_{i}, 1 \leq i \leq m$, is adjacent to each vertex that is adjacent to $v$ in $G$.

The $m$-shadow graph $D_{m}(G)$ of a connected graph $G$ is constructed by taking $m$ copies of $G$, say $G_{1}, G_{2}, \ldots, G_{m}$, then join each vertex $u$ in $G_{i}$ to the neighbors of the corresponding vertex $v$ in $G_{j}, 1 \leq i, j \leq m$.

Proposition $1.1([14])$. $E\left(\operatorname{Spl}_{m}(G)\right)=\sqrt{1+4 m} E(G)$. 
Proposition $1.2([14])$. $E\left(D_{m}(G)\right)=m E(G)$.

\section{Equienergetic Graphs}

Theorem 2.1. $\operatorname{Spl}_{2}(G)$ and $D_{3}(G)$ are equienergetic.

Proof. Let $G$ be any graph with $n$ vertices. Then, $D_{3}(G)$ and $\operatorname{Spl}_{2}(G)$ are graphs with $3 n$ vertices. According to Proposition 1.1 and Proposition 1.2,

$$
E\left(\operatorname{Spl}_{2}(G)\right)=\sqrt{1+4(2)} E(G)=3 E(G)=E\left(D_{3}(G)\right) .
$$

Example 2.1. Consider $\operatorname{Spl}_{2}\left(C_{4}\right)$ and $D_{3}\left(C_{4}\right)$,

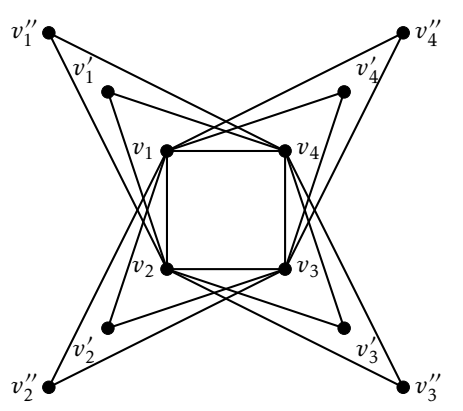

$\operatorname{Spl}_{2}\left(C_{4}\right)$

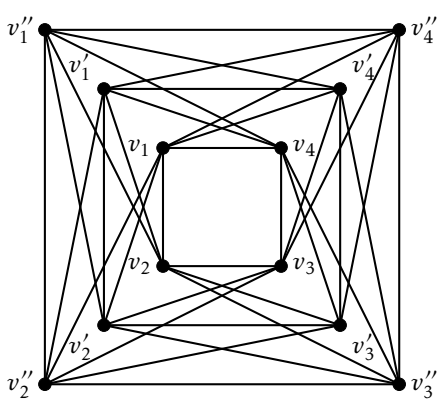

$D_{3}\left(C_{4}\right)$

FIGURE 1

$$
\begin{aligned}
& \begin{array}{llllllllllll}
v_{1} & v_{2} & v_{3} & v_{4} & v_{1}^{\prime} & v_{2}^{\prime} & v_{3}^{\prime} & v_{4}^{\prime} & v_{1}^{\prime \prime} & v_{2}^{\prime \prime} & v_{3}^{\prime \prime} & v_{4}^{\prime \prime}
\end{array} \\
& \boldsymbol{v}_{1}\left[\begin{array}{llllllllllll}
0 & 1 & 0 & 1 & 0 & 1 & 0 & 1 & 0 & 1 & 0 & 1
\end{array}\right] \\
& \begin{array}{l|llllllllllll}
\boldsymbol{v}_{\mathbf{2}} & 1 & 0 & 1 & 0 & 1 & 0 & 1 & 0 & 1 & 0 & 1 & 0
\end{array} \\
& \begin{array}{l|llllllllllll}
\boldsymbol{v}_{3} & 0 & 1 & 0 & 1 & 0 & 1 & 0 & 1 & 0 & 1 & 0 & 1
\end{array} \\
& \begin{array}{l|llllllllllll}
\boldsymbol{v}_{4} & 1 & 0 & 1 & 0 & 1 & 0 & 1 & 0 & 1 & 0 & 1 & 0
\end{array} \\
& \begin{array}{l|llllllllllll}
\boldsymbol{v}_{1}^{\prime} & 0 & 1 & 0 & 1 & 0 & 0 & 0 & 0 & 0 & 0 & 0 & 0
\end{array}
\end{aligned}
$$

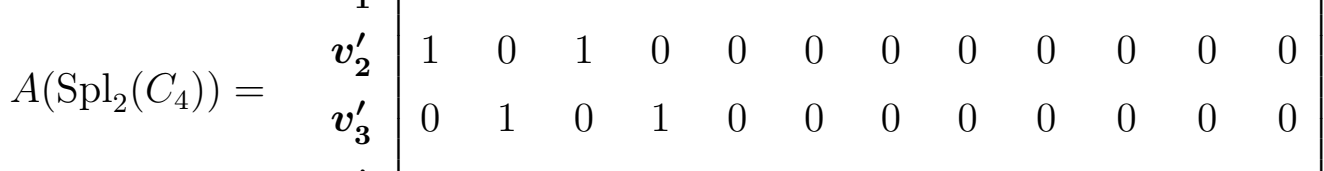

$$
\begin{aligned}
& \begin{array}{l|llllllllllll}
\boldsymbol{v}_{4}^{\prime} & 1 & 0 & 1 & 0 & 0 & 0 & 0 & 0 & 0 & 0 & 0 & 0
\end{array} \\
& \begin{array}{l|llllllllllll}
\boldsymbol{v}_{1}^{\prime \prime} & 0 & 1 & 0 & 1 & 0 & 0 & 0 & 0 & 0 & 0 & 0 & 0
\end{array} \\
& \begin{array}{lllllllllllll}
\boldsymbol{v}_{\mathbf{2}}^{\prime \prime} & 1 & 0 & 1 & 0 & 0 & 0 & 0 & 0 & 0 & 0 & 0 & 0
\end{array} \\
& \begin{array}{lllllllllllll}
\boldsymbol{v}_{\mathbf{3}}^{\prime \prime} & 0 & 1 & 0 & 1 & 0 & 0 & 0 & 0 & 0 & 0 & 0 & 0
\end{array} \\
& \boldsymbol{v}_{\boldsymbol{4}}^{\prime \prime}\left[\begin{array}{llllllllllll}
1 & 0 & 1 & 0 & 0 & 0 & 0 & 0 & 0 & 0 & 0 & 0
\end{array}\right]
\end{aligned}
$$


Therefore, $\operatorname{spec}\left(\operatorname{Spl}_{2}\left(C_{4}\right)\right)=\left(\begin{array}{ccccc}2 & -2 & 4 & -4 & 0 \\ 1 & 1 & 1 & 1 & 8\end{array}\right)$. Here,

$$
\begin{aligned}
& E\left(\operatorname{Spl}_{2}\left(C_{4}\right)\right)=12 \text {, }
\end{aligned}
$$

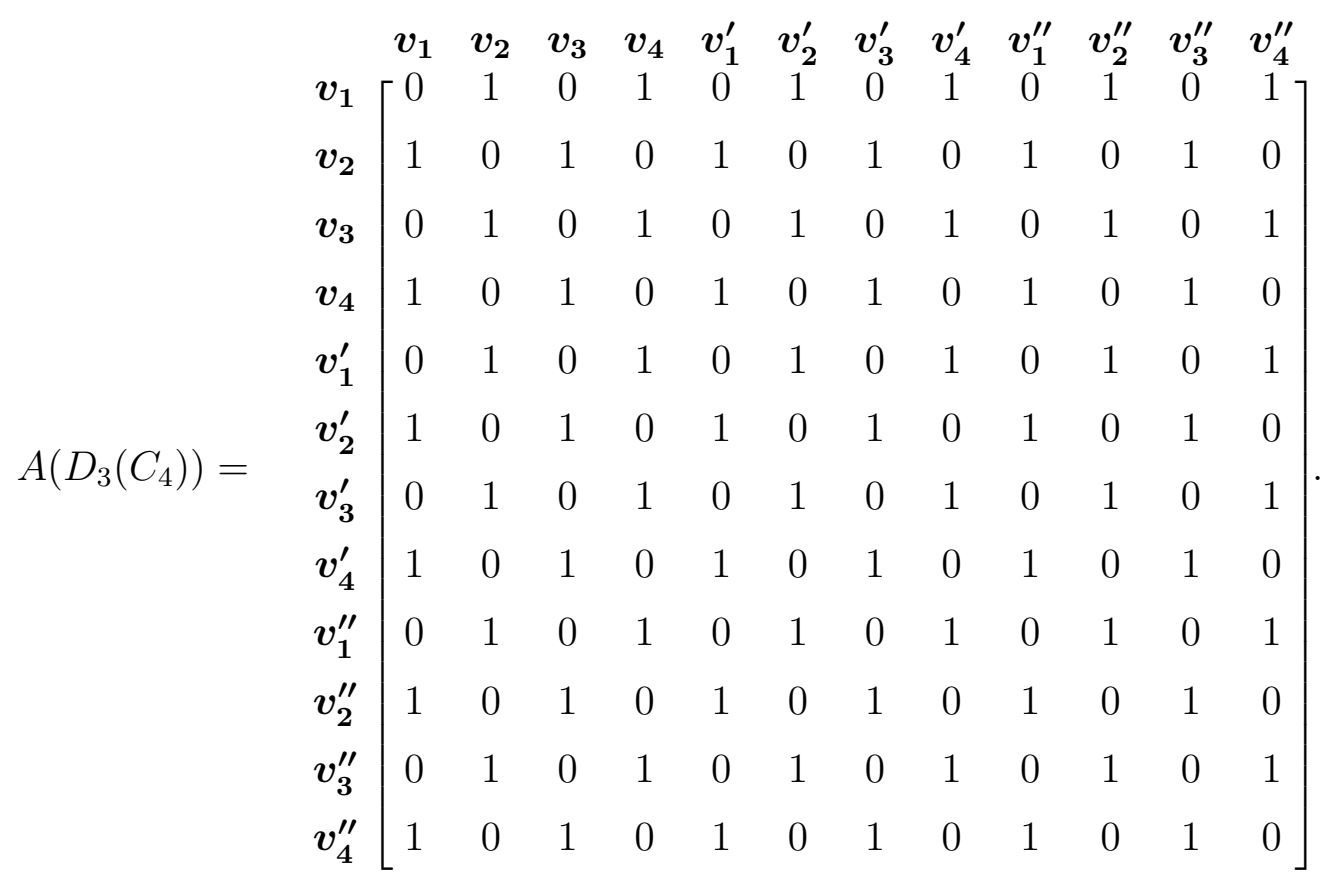

Therefore, $\operatorname{spec}\left(D_{3}\left(C_{4}\right)\right)=\left(\begin{array}{ccc}6 & -6 & 0 \\ 1 & 1 & 10\end{array}\right)$. Here, $E\left(D_{3}\left(C_{4}\right)\right)=12$. Hence, $\operatorname{Spl}_{2}\left(C_{4}\right)$ and $D_{3}\left(C_{4}\right)$ are equienergetic.

\section{Hyperenergetic Graphs}

Theorem 3.1. $S^{\prime}\left(K_{n}\right)$ is hyperenergetic if and only if $n \geq 6$.

Proof. Consider a complete graph $K_{n}$ on $n$ vertices. Then, $S^{\prime}\left(K_{n}\right)$ is a graph with $2 n$ vertices. It is obvious that energy of complete graph with $2 n$ vertices is $2(2 n-1)$. Now, if $S^{\prime}\left(K_{n}\right)$ is hyperenergetic, then

$$
\begin{aligned}
E\left(S^{\prime}\left(K_{n}\right)\right)>2(2 n-1) & \Leftrightarrow \sqrt{5}\left(E\left(K_{n}\right)\right)>2(2 n-1) \\
& \Leftrightarrow \sqrt{5}(2(n-1))>2(2 n-1) \\
& \Leftrightarrow n>\frac{\sqrt{5}-1}{\sqrt{5}-2} \\
& \Leftrightarrow n \geq 6 .
\end{aligned}
$$

Example 3.1. Consider complete graph $K_{6}$ and $S^{\prime}\left(K_{6}\right)$. 

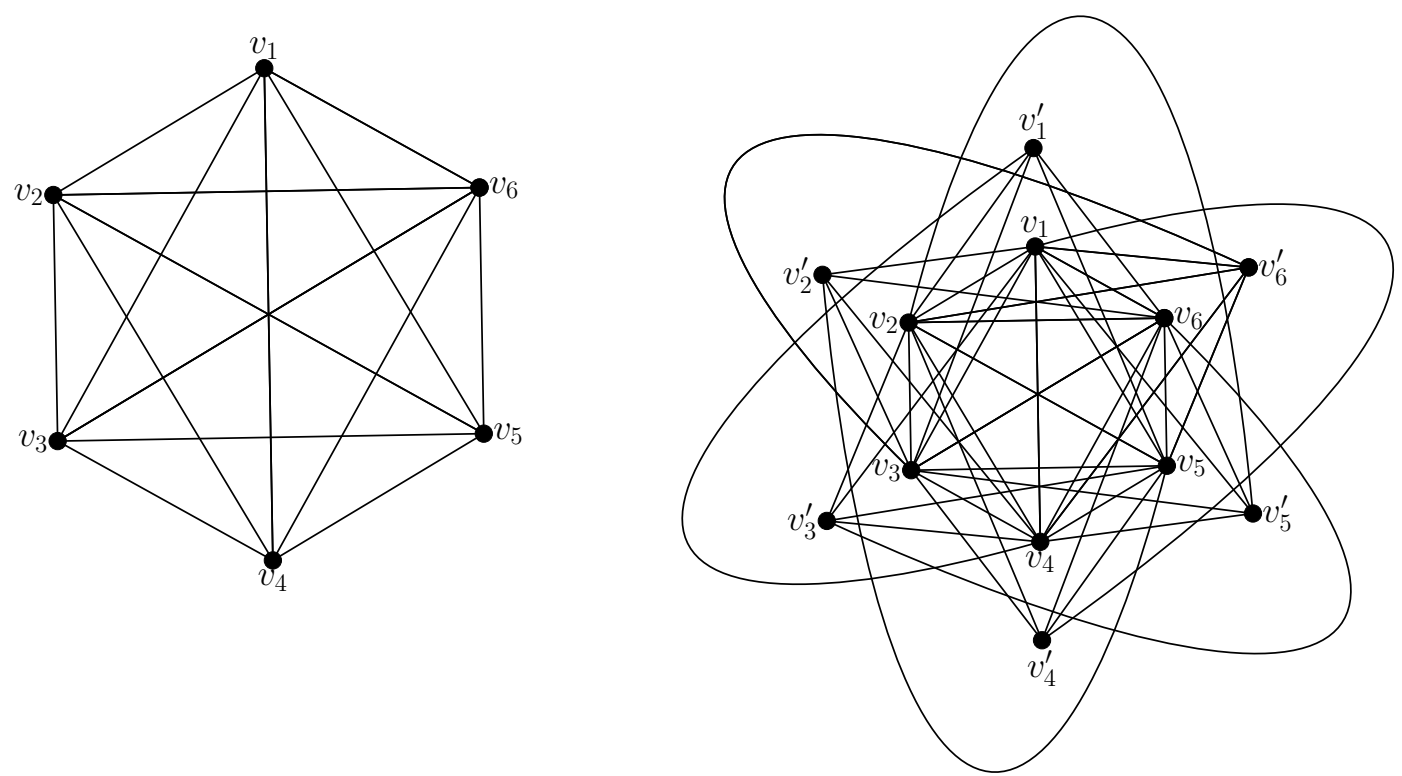

$K_{6}$

$S^{\prime}\left(K_{6}\right)$

FiguRE 2

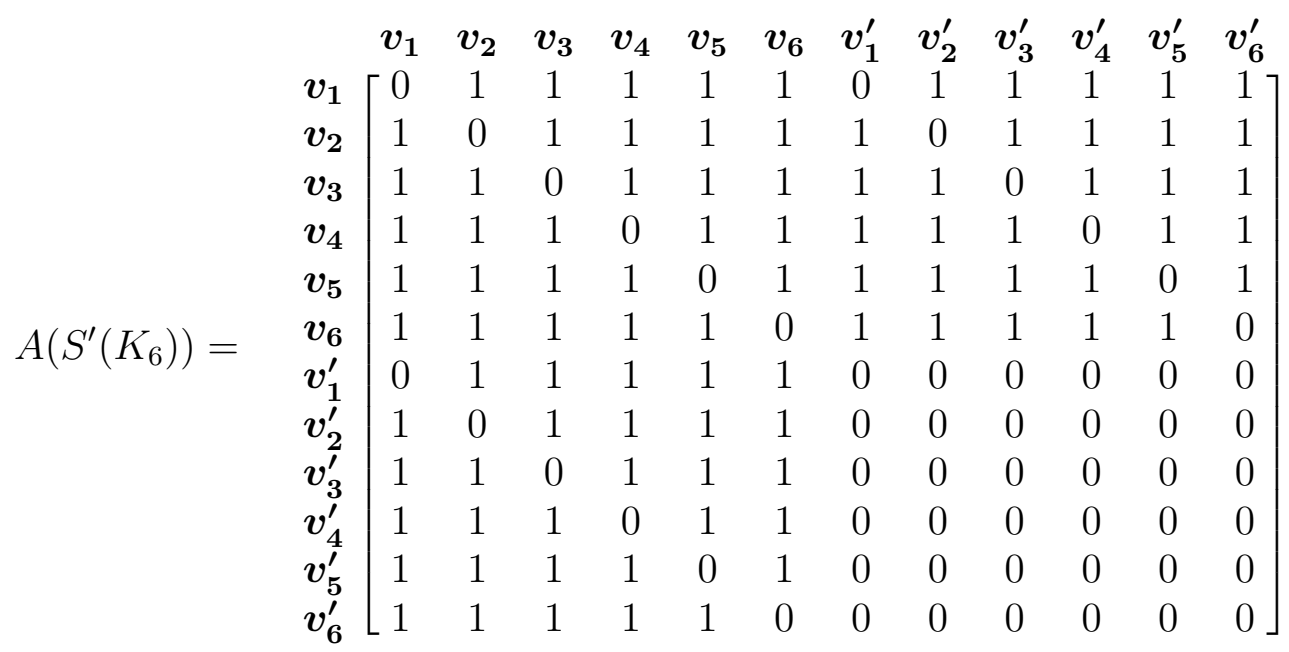

Hence,

$$
\operatorname{spec}\left(S^{\prime}\left(K_{6}\right)\right)=\left(\begin{array}{cccc}
\frac{-1+\sqrt{5}}{2} & \frac{-1-\sqrt{5}}{2} & \frac{5+5 \sqrt{5}}{2} & \frac{5-5 \sqrt{5}}{2} \\
5 & 5 & 1 & 1
\end{array}\right)
$$


Here,

$$
\begin{aligned}
E\left(S^{\prime}\left(K_{6}\right)\right)=10 \sqrt{5} & \Rightarrow E\left(S^{\prime}\left(K_{6}\right)\right)>22 \\
& \Rightarrow E\left(S^{\prime}\left(K_{6}\right)\right)>E\left(K_{12}\right) \\
& \Rightarrow S^{\prime}\left(K_{6}\right) \text { is hyperenergetic. }
\end{aligned}
$$

The following is a graph of $E\left(S^{\prime}\left(K_{n}\right)\right)$ and $E\left(K_{2 n}\right)$ which helps to understand that $S^{\prime}\left(K_{n}\right)$ is hyperenergetic when $n \geq 6$.

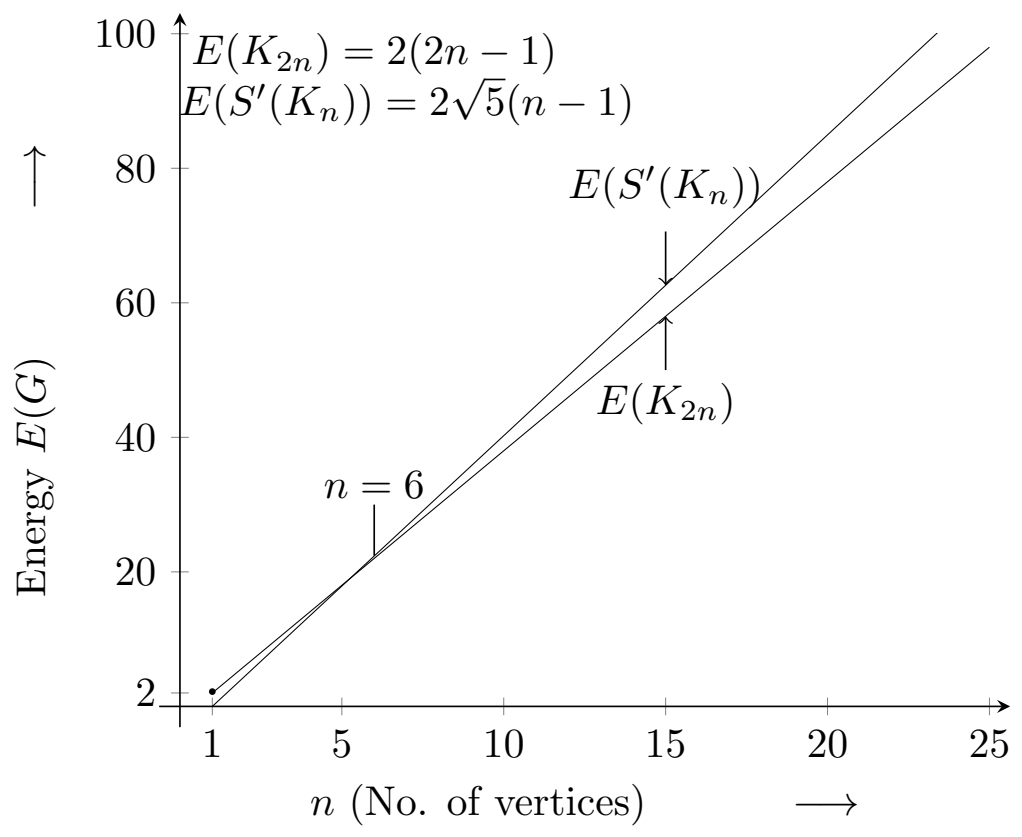

FiguRE 3

The natural question arises: Are there any graphs which are equienergetic and hyperenergetic as well? To answer this question we prove following corollary.

Corollary 3.1. $D_{3}\left(S^{\prime}\left(K_{n}\right)\right)$ and $\operatorname{Spl}_{2}\left(S^{\prime}\left(K_{n}\right)\right)$ are equihyperenergetic graphs for $n \geq 9$.

Proof. As we have discussed in Theorem 3.1, $S^{\prime}\left(K_{n}\right)$ is a graph with $2 n$ vertices. Therefore, $D_{3}\left(S^{\prime}\left(K_{n}\right)\right)$ is a graph with $6 n$ vertices. To prove above result we show that $D_{3}\left(S^{\prime}\left(K_{n}\right)\right)$ is hyperenergetic if and only if $n \geq 9$.

If $D_{3}\left(S^{\prime}\left(K_{n}\right)\right)$ is hyperenergetic then

$$
\begin{aligned}
E\left(D_{3}\left(S^{\prime}\left(K_{n}\right)\right)\right)>2(6 n-1) & \Leftrightarrow 3 E\left(S^{\prime}\left(K_{n}\right)\right)>2(6 n-1) \\
& \Leftrightarrow 3 \sqrt{5}\left(E\left(K_{n}\right)\right)>2(6 n-1) \\
& \Leftrightarrow 3 \sqrt{5}(2(n-1))>2(6 n-1)
\end{aligned}
$$




$$
\begin{aligned}
& \Leftrightarrow n>\frac{3 \sqrt{5}-1}{3 \sqrt{5}-6} \\
& \Leftrightarrow n \geq 9 .
\end{aligned}
$$

Hence, $D_{3}\left(S^{\prime}\left(K_{n}\right)\right)$ is hyperenergetic for $n \geq 9$. Therefore, according to Theorem 2.1, $D_{3}\left(S^{\prime}\left(K_{n}\right)\right)$ and $\operatorname{Spl}_{2}\left(S^{\prime}\left(K_{n}\right)\right)$ are equihyperenergetic for $n \geq 9$.

\section{Hypoenergetic Graphs}

Theorem 4.1. $D_{m}\left(K_{1, n}\right)$ is hypoenergetic.

Proof. Consider star graph $K_{1, n}$ on $n$ vertices. Then $E\left(K_{1, n}\right)=2 \sqrt{n}$. Now, $D_{m}\left(K_{1, n}\right)$ is a graph with $m(n+1)$ vertices. As,

$$
\begin{aligned}
n>1 & \Rightarrow(n-1)^{2}>0 \\
& \Rightarrow n^{2}-2 n+1>0 \\
& \Rightarrow n^{2}+2 n+1>4 n \\
& \Rightarrow 4 n<(n+1)^{2} \\
& \Rightarrow 2 \sqrt{n}<(n+1) \\
& \Rightarrow m(2 \sqrt{n})<m(n+1) .
\end{aligned}
$$

According to Proposition 1.2, we have $E\left(D_{m}\left(K_{1, n}\right)\right)=m E\left(K_{1, n}\right)=m(2 \sqrt{n})<$ $m(n+1)$. Hence, $D_{m}\left(K_{1, n}\right)$ is hypoenergetic.

Example 4.1. Consider star graph $K_{1,4}$ and $D_{2}\left(K_{1,4}\right)$ (see Figure 4). Therefore, $\operatorname{spec}\left(D_{2}\left(K_{1,4}\right)\right)=\left(\begin{array}{ccc}4 & -4 & 0 \\ 1 & 1 & 8\end{array}\right)$. Hence, $E\left(D_{2}\left(K_{1,4}\right)\right)=8<10$ and $D_{2}\left(K_{1,4}\right)$ is hypoenergetic.
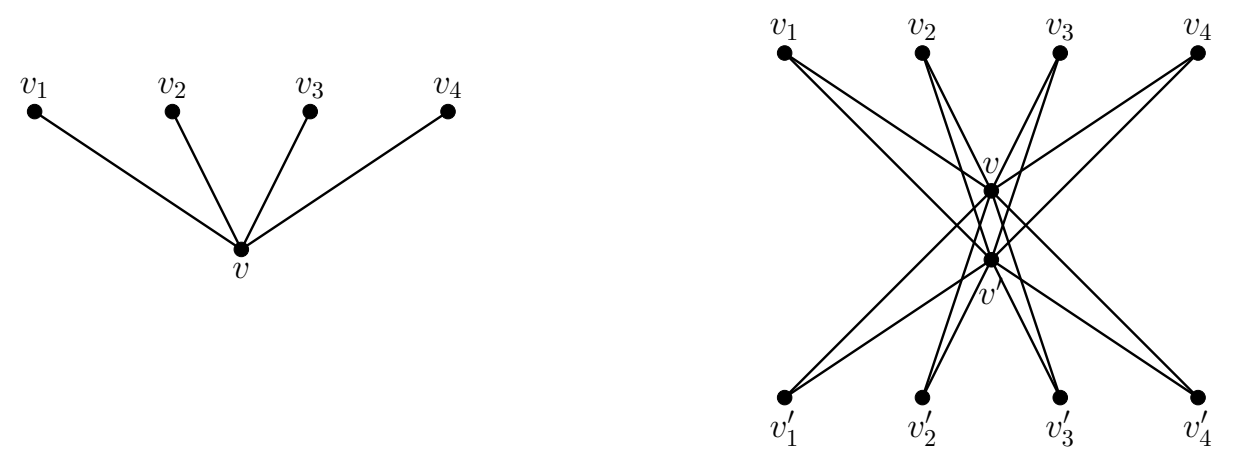

$K_{1,4}$

$$
D_{2}\left(K_{1,4}\right)
$$

FiguRE 4 


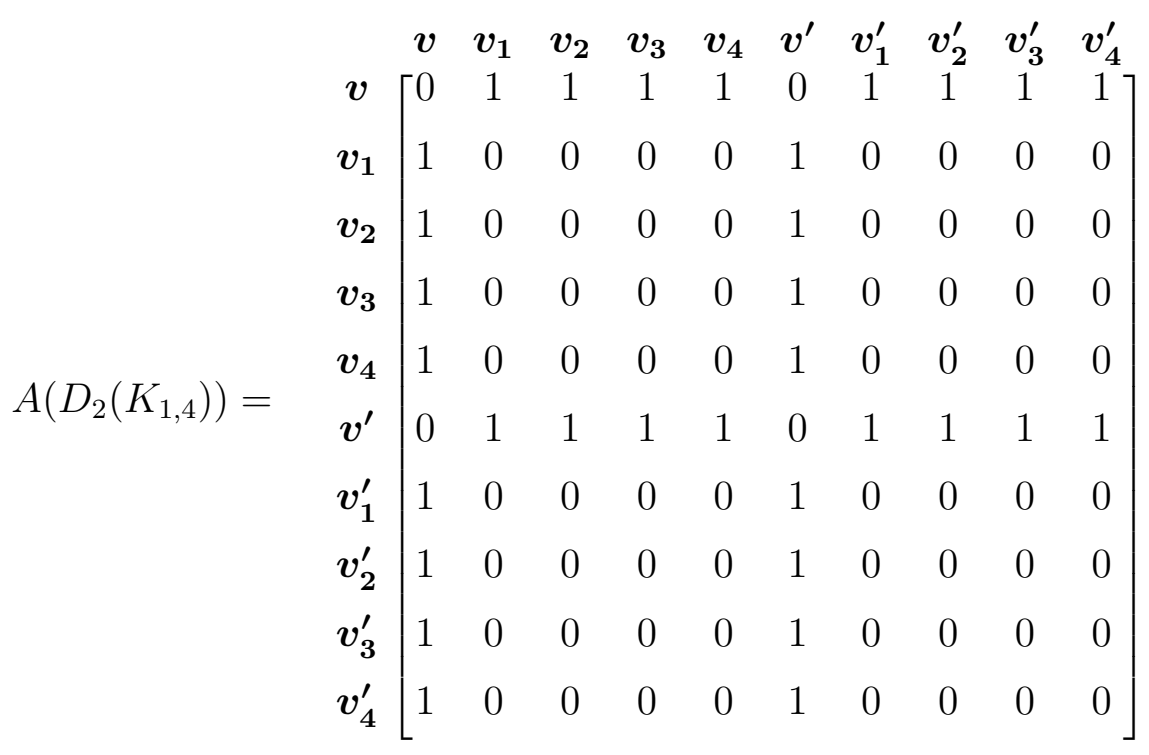

The following graph on Figure 5 is a graph of $n$ and $E(G)$ which helps to understand that $D_{2}\left(K_{1, n}\right)$ is hypoenergetic.

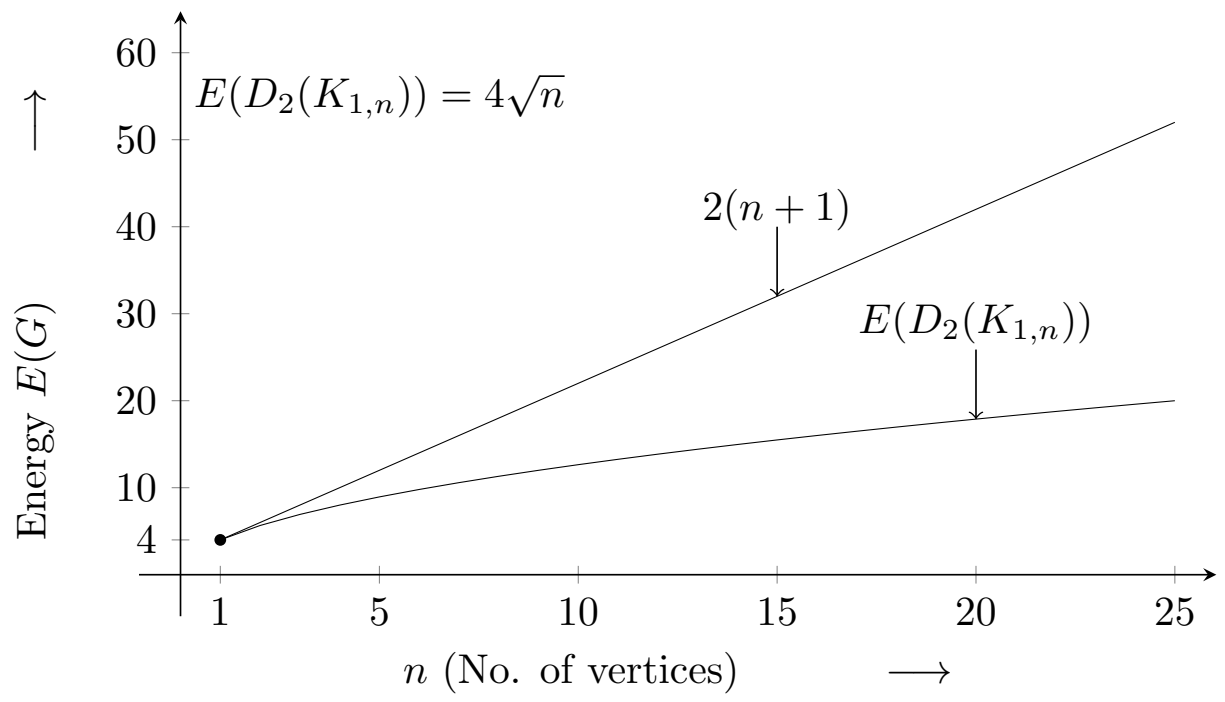

FiguRE 5

The natural question arises: are there any graphs which are equienergetic as well as hypoenergetic? We call such graphs as equihypoenergetic. To answer this question we prove following corollary.

Corollary 4.1. $D_{3}\left(K_{1, n}\right)$ and $\operatorname{Spl}_{2}\left(K_{1, n}\right)$ are equihypoenergertic graphs. 
Proof. It is obvious that from Theorem 4.1, $D_{3}\left(K_{1, n}\right)$ is hypoenergetic and from Theorem 2.1, $D_{3}\left(K_{1, n}\right)$ and $\operatorname{Spl}_{2}\left(K_{1, n}\right)$ are equienergetic. Hence, $D_{3}\left(K_{1, n}\right)$ and $\operatorname{Spl}_{2}\left(K_{1, n}\right)$ are equihypoenergertic graphs.

Acknowledgements. The present work is a part of the research work carried out under Major Research Project No. IQAC/GJY/MRP/OCT/2016/1670-A, dated: 4th October, 2016 funded by Saurashtra University-Rajkot (Gujarat), India.

The authors thank the anonymous referees for their valuable suggestions leading to the improvement of the original manuscript.

\section{REFERENCES}

[1] R. Balakrishnan and K. Ranganathan, A Textbook of Graph Theory, Springer, New York, 2000.

[2] V. Brankov, D. Stevanović and I. Gutman, Equienergetic chemical trees, Journal of the Serbian Chemical Society 69 (2004), 549-553.

[3] D. M. Cvetković and I. Gutman, The algebraic multiplicity of the number zero in the spectrum of a bipartite graph, Mat. Vesnik (Beograd) 9 (1972), 141-150.

[4] D. M. Cvetković and I. Gutman, The computer system graph: a useful tool in chemical graph theory, J. Comput. Chem. 7 (1986), 640-644.

[5] D. M. Cvetković, P. Rowlison and S. Simić, An Introduction to the Theory of Graph Spectra, Cambridge University Press, Cambridge, 2010.

[6] I. Gutman, The energy of a graph, Ber. Math. Statist. Sekt. Forschungszentrum Graz 103 (1978), 1-22.

[7] I. Gutman, Hyperenergetic molecular graphs, Journal of the Serbian Chemical Society 64 (1999), 199-205.

[8] I. Gutman, Open problems for equienergetic graphs, Iranian Journal of Mathematical Chemistry 6 (2015), 185-187.

[9] I. Gutman, S. Z. Firoozabadi, J. A. de la Pen̈a and J. Rada, On the energy of regular graphs, MATCH Commun. Math. Comput. Chem. 57 (2007), 435-442.

[10] X. Li, Y. Shi and I. Gutman, Graph Energy, Springer, New York, 2012.

[11] O. Milijković, B. Furtula, S. Radenković and I. Gutman, Equienergetic and almost equienergetic trees, MATCH Commun. Math. Comput. Chem. 61 (2009), 451-461.

[12] H. S. Ramane, I. Gutman, H. B. Walikar and S. B. Halkarni, Equienergetic complement graphs, Kragujevac J. Math. 27 (2005), 67-74.

[13] H. S. Ramane, H. B. Walikar, S. B. Rao, B. D. Acharya, P. R. Hampiholi, S. R. Jog and I. Gutman, Equienergetic graphs, Kragujevac J. Math. 26 (2004), 1-22.

[14] S. K. Vaidya and K. M. Popat, Energy of $m$-splitting and $m$-shadow graphs, Far East Journal of Mathematical Sciences 102 (2017), 1571-1578.

[15] S. K. Vaidya and K. M. Popat, Some new results on energy of graphs, MATCH Commun. Math. Comput. Chem. 77 (2017), 589-594.

[16] H. B. Walikar, H. S. Ramane and P. Hampiholi, On the energy of a graph, in: R. Balakrishnan, H. M. Mulder, A. Vijayakumar (Eds.), Graph Connections, Allied Publishers, New Delhi, 1999, $120-123$. 
${ }^{1}$ Department of Mathematics,

SAURASHTRA UNIVERSITY,

RAJKOT(GUJARAT), INDIA

Email address: samirkvaidya@yahoo.co.in

${ }^{2}$ Department of MCA,

Atmiya Institute of Technology \& Science,

RAJKot(GuJARAT), IndiA

Email address: kalpeshmpopat@gmail.com 